\title{
Effect of Incandescent Light on Some Morphological Characters of Cucumber Plant (Cucumis sativus L.)
}

\author{
Wafaa K. Taia and Salha M. Fadan \\ Botany Department, Faculty of Science, Alexandria University, \\ Alexandria- Egypt \\ College of Education for Girls, Scientific Section, El-Malaz, Al-Riyadh, \\ Saudi Arabia
}

\begin{abstract}
Seeds of cucumber were cultivated under the influence of daily exposure to incandescent light originated from $100 \mathrm{~W}, 220 \mathrm{~V}$ lamp (normal tungsten filament bulb). The seeds were divided into five categories; $0,1,2,3$ and $4 \mathrm{~ms}$ far from the lamp. Each category is subdivided into four groups and exposed to the lamp for $(1 / 4,1 / 2,3 / 4$ and 1 hour daily). Seedlings are examined for plant lengths, plumule: radicle ratio, leaf colour, area and numbers, radicle shapes and secondary roots status after 3 weeks of germination, while analyses for fresh, dry weight, photosynthetic pigments and sugar contents carried out after 45 days of plantation. The results revealed that plant length, leaf area, fresh weight and photosynthetic pigments have been significantly affected, while sugar content and dry weight are insignificantly affected by the exposure to the lamp. To show the most optimum distance and time of exposure for each investigated character the results were analyzed using Response Surface Analysis (RSA) and SpineFitting (SF) analysis and an ANN models.
\end{abstract}

Keywords: Growth params, Leaf area, Light bulb , Morphological characters - Photosynthetic pigments, Sugar contents.

\section{Introduction}

The use of modern technologies and different types of lamps causes continuous exposure to electromagnetic fields (EMFs) and photoelectric waves, generated from different sources. These exposures may affect the public health and living creatures as well as plant appearance and 
sometimes to species diversity and extinction. Many Works were done to investigate the effect of both electric and magnetic fields on living creatures. The international programme of chemical safety ${ }^{[1]}$, pointed to the emission of small amount of ultra violet rays from home lamps, and this may cause some disorders to living creatures. In spite of that, they considered the amount of UV rays emits from the tungsten filament lamps are generally negligible with the human health ${ }^{[1]}$, and they continued their investigations on the effects of other sources of UV rays. The same was mentioned by ${ }^{[2]}$, as the electric current passes through the low pressure gases, it emits quite a bit of ultra violet rays.

The EMF Interface ${ }^{[3]}$, studied the harmful effect of electric and magnetic field originated in the wires due to switching light and appliance on and off. The research teams concluded that peoples must stay 4 feet away from all electrical devices and wiring in the bedrooms, including digital clocks and lights such as fluorescent, halogen and high intensity reading lights to avoid the exposure to electromagnetic fields. They pointed out to the presence of an electrical field which radiate all the time in lamp which may affect all the living organisms present.

Bugbee ${ }^{[4]}$, studied the differences in radiation quality from the six common electric lamps; Low Pressure Sodium (LPS), High Pressure Sodium (HPS), Incandescent (INC), Cool White Fluorescent (CWF), and Red Light-Emitting Diode (LED); compared with sunlight and their effects on plant growth and photosynthetic pigments contents. He found that radiation quality alters plant growth through its effect on internodes elongation, while it has little effect on photosynthetic rate.

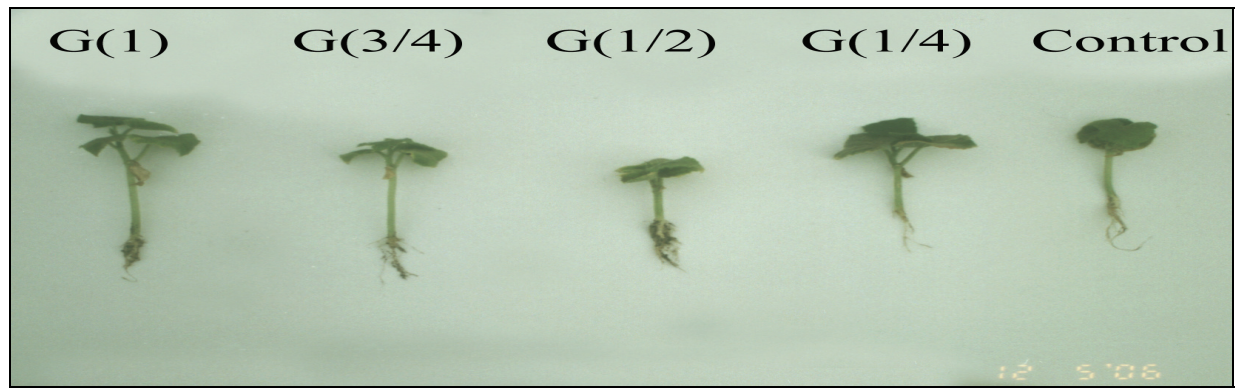

Photo 1. Photographs of seedlings of the different exposure times and distances of germinated seeds of Cucumis sativu.

Berekly ${ }^{[5]}$, pointed to the release of mercury into the environment from the regular incandescent light bulbs which harm the environment. 
Afterwards, ${ }^{[6]}$, found that the incandescent light is healthier than the other sources of electrical lights. As the incandescent light bulbs consist of a glass bulb, emptied from air and filled with an inert gas like argon, in which a spiraled super-thin tungsten filament is heated by electricity until it glows.

However, the incandescent light bulbs may emit a bit of both ultra violet rays and mercury beside heat into our environment ${ }^{[1]}$ and can harm both plants and animals. For that we started our experiment to investigate the effect of the exposure to an ordinary $100 \mathrm{~W}$ electric lamp (normal tungsten filament bulb) as one of the most widespread source of light used, for fixed times daily, during germination of Cucumber seeds on some growth characters, photosynthetic pigments and sugar contents.

\section{Materials and Methods}

Seeds of Cucumis sativus L. (Cucumber plant) were selected as a sample plant for its fast growth and easy observable characters. The seeds have been divided into two categories, the first one contains 500 seeds, is dry seeds. This category has been exposed to an electric lamp $(\mathrm{F}=100 \mathrm{~W}, 220 \mathrm{~V})$ during the germination period, which lasts for three weeks, from different distances: 1, 2, 3 or 4 meters. At each distance the pots exposed for $1 / 4,1 / 2,3 / 4$ or one hour daily till the emergence of the first two foliage leaves. The second one is the Blanc which germinated under normal conditions. Twenty five seeds from all the above mentioned divisions (Fig.1) with different exposure times are planted in pots $(25 \times 27 \mathrm{~cm}$.), and filled with 1:1 sand: Pitmos each with five replicas. The pots have been put in circles to ensure that all of them are exposed to the same force. A 100 Watt electric lamp $220 \mathrm{~V}$. has been deposited in the middle of each circle, all pots are irrigated with $500 \mathrm{ml}$. tap water every $24 \mathrm{~h}$.

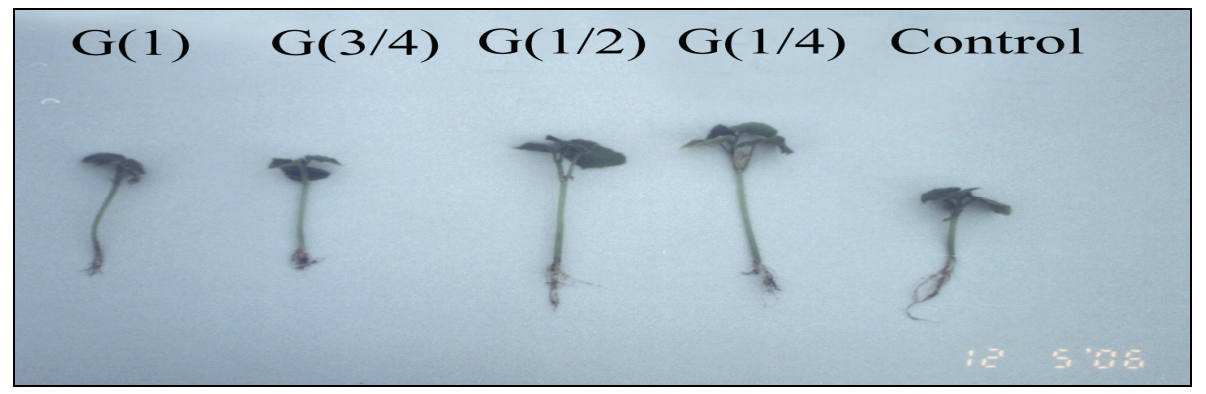

Photo 2. Photographs of seedlings of the different exposure times and distances of germinated seeds of Cucumis sativu. 
Measurements and descriptions are taken for ten seedlings after 3 weeks of germination, while analyses have been carried out in young plants arisen after 45 days from the beginning of the experiment. Means of the measurements are calculated and listed in the Table 1. Characters investigated are as follows:

1 - Measuring the length of the seedlings from the end of the top to the growing point in the root in $\mathrm{cm}$.

2- Ratio between radicle and plumule lengths ( $\mathrm{R}: \mathrm{P})$.

3- Radicle shape.

4- Secondary root status.

5- Color of the first foliage leaves.

6- Total number of leaves after 45 days.

7- Leaf area for five middle leaves from each pot.

8- Fresh and dry weights for ten plants from each treatment (after 45 days) in gram.

9- Photosynthetic pigments (chl.a, b, total chlorophyll and carotenoides) ${ }^{[7]}$. 10- Total sugar content ${ }^{[8]}$.

The results have been analyzed using Response Surface Analysis

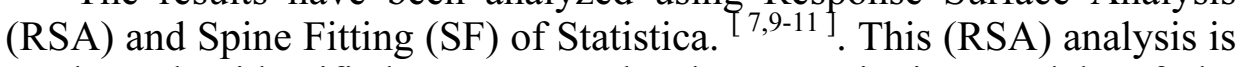
used to the identified pattern to develop quantitative models of the investigated phenomenon. Specifically, the curve revealed by the smoothing procedure often consists of segments that cannot easily be described by one function (e.g., such as a particular polynomial or logarithmic function). However, the segmentation, and the nature of the component curves (in the consecutive segments) may contain interpreTable information about the investigated phenomenon, and a linear or nonlinear piecewise regression function can be developed to account for (and predict) the process in question. The model suggested by the results of such analyses can then be quantitatively verified in a nonlinear estimation analysis.

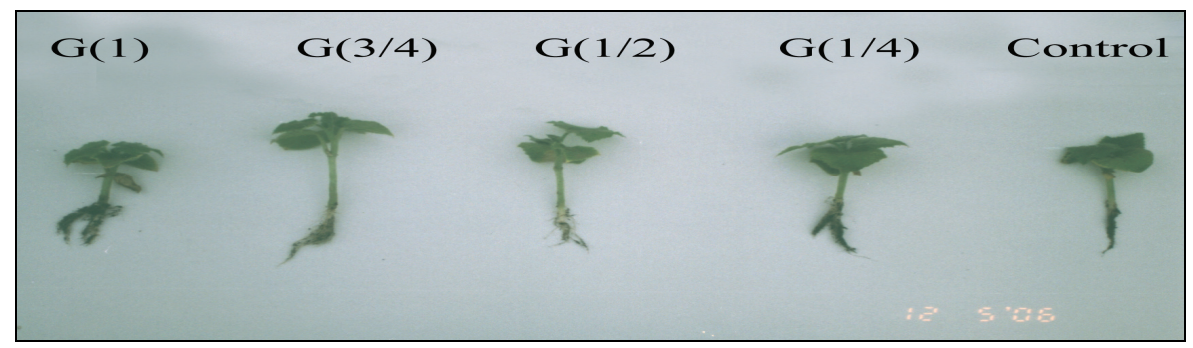

Photo 3. Photographs of seedlings of the different exposure times and distances of germinated seeds of Cucumis sativu. 
For bi-variant data sets (correlations that involve two variables), to determine the curve, the Spine procedure solves cubic equations for every point at a regular interval. A minimum of at least 3 data points are necessary to perform a Spine fit; the algorithm ignores overlapping data points.

\section{Results}

The results are summarized in the Tables $1 \& 2$. From photographs $1-4$, it can be noticed that the emerged seedlings of one $m$ distance pots were taller than the control in the four times of exposure. Whereas, the plants at the 2, 3 and $4 \mathrm{~m}$ far, were either shorter than, or nearly equal to, the control plants. The length of the seedlings is due to the expanded plumule as obvious from $\mathrm{P}: \mathrm{R}$ ratio. The radicles are mostly slightly curved but in those exposed to lamp at $2 \mathrm{~m}$ distance at all exposure times, and $4 \mathrm{~m}$. distance for $1 / 2 \mathrm{~h}$. and $3 / 4 \mathrm{~h}$ become straight. Secondary roots are few or moderate in density, except in 1/4 hour exposure time at 3 and $4 \mathrm{~m}$ distance from the lamp. While $1 \mathrm{~h}$. exposure time at $4 \mathrm{~ms}$ distance, they become dense (Photos 1-4).

The leaves are either olive green, or green which after 45 days, five or four foliage leaves emerged, except in 1 and $2 \mathrm{~m}$ distance pots, all exposure times, there were 3 foliage leaves only, which are less than the control. The total number of leaves becomes as the control in the 3 and 4 ms distances pots, in all times of exposure.

The fresh weight of the plants increased in most of the exposure times and distance (Table 1) while the dry weight was not affected greatly.

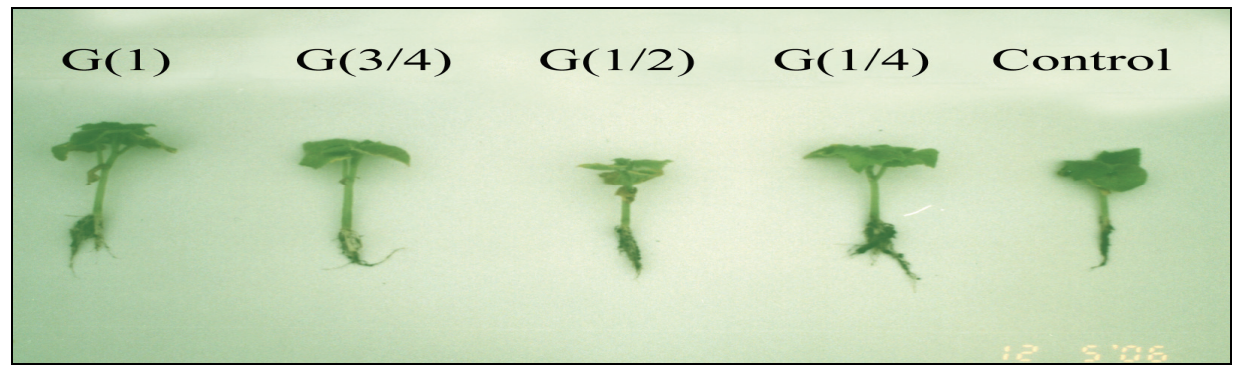

Photo 4. Photographs of seedlings of the different exposure times and distances of germinated seeds of Cucumis sativu. 
Photosynthetic pigments were affected as well, since chlorophyll a has increased in short distance plants in all exposure times and decreased in long distance $(4 \mathrm{~m})$ pots at the first three exposure times beside the 3 $\mathrm{m}, 1 / 4 \mathrm{~h}$ exposed plants. Meanwhile chlorophyll $\mathrm{b}$, total chlorophyll and carotenoides contents decreased in most of the treated plants, except in 1 and $3 / 4 \mathrm{~h}$ exposure $1 \mathrm{~m}$ distance and $3 / 4 \mathrm{~h} 2 \mathrm{~m}$ distance. The total sugar contents were not affected by any exposure time or distance.

Table 1. Characters investigated in seedlings and young plants of germinated seeds of Cucumis sativus.

\begin{tabular}{|c|c|c|c|c|c|c|c|c|c|c|c|c|c|c|c|c|c|}
\hline \multirow{2}{*}{\begin{tabular}{|l|} 
Dist. \\
T. $\rightarrow$ \\
Ch. $\downarrow$
\end{tabular}} & \multirow{2}{*}{$\frac{\cdot}{0}$} & \multicolumn{4}{|c|}{$1 \mathrm{~m}}$. & \multicolumn{4}{|c|}{$2 \mathrm{~m}$. } & \multicolumn{4}{|c|}{$3 \mathrm{~m}$. } & \multicolumn{4}{|c|}{$4 \mathrm{~m}}$. \\
\hline & & 1h. & 3/4h. & $1 / 2 \mathrm{~h}$. & $1 / 4 \mathrm{~h}$. & 1h. & $3 / 4 \mathrm{~h}$. & $1 / 2 \mathrm{~h}$ & $1 / 4 h$ & $1 \mathrm{~h}$. & $3 / 4 h$. & $1 / 2 h$. & $1 / 4 \mathrm{~h}$. & 1h. & 3/4h. & $1 / 2 \mathrm{~h}$. & $1 / 4 \mathrm{~h}$. \\
\hline Plant $\mathrm{L}$. & 7.5 & 14.3 & 12.0 & \begin{tabular}{|l|}
10.3 \\
\end{tabular} & 10.5 & 6 & 5.5 & 11.2 & 10.8 & 5.7 & 7.7 & 8.7 & 5.7 & 6 & 5.5 & 7 & 7.2 \\
\hline $\mathbf{P} / \mathbf{R}$ & 2.5 & 3 & 2.2 & 4 & 3.4 & 5 & 4.5 & 3 & 3 & 2 & 2 & 3 & 1.5 & 1.6 & 1.2 & 3.2 & 2.8 \\
\hline \begin{tabular}{|l|} 
Rad. \\
shape
\end{tabular} & C & C & C & C & C & St & St & St & St & C & C & StC & C & St C & St & St & C \\
\hline 2ry.R. & Sp & Sp & M & Sp & Sp & Sp & Sp & Sp & Sp & M & M & M & D & D & M & $\mathbf{M}$ & D \\
\hline Leaf color & Ol & O & Ol & G & G & Ol & Ol & OI & OI & Ol & Ol & Ol & G & G & G & G & G \\
\hline No. of $L$. & 5 & 3 & 3 & 3 & 3 & 4 & 4 & 4 & 4 & 5 & 5 & 4 & 5 & 5 & 5 & 4 & 5 \\
\hline Leaf area & 8.67 & 10.67 & 13.33 & 8.67 & 7 & 14 & 16.33 & 11.67 & 12.67 & 11.33 & 14.33 & 15.67 & 12.33 & 17.33 & 12.33 & 14.0 & 12.33 \\
\hline Fresh wt. & 1.84 & 2.37 & 2.43 & 1.6 & 1.52 & 2.11 & 2.39 & 2.27 & 2.6 & 2.09 & 2.26 & 2.57 & 2.42 & 2.43 & 2.16 & 1.95 & 2.68 \\
\hline Dry wt. & 0.22 & 0.23 & 0.23 & \begin{tabular}{|l|}
0.18 \\
\end{tabular} & 0.16 & 0.21 & 0.27 & 0.22 & 0.26 & 0.22 & 0.24 & 0.29 & 0.27 & 0.29 & \begin{tabular}{|l|l|}
0.24 \\
\end{tabular} & 0.21 & 0.31 \\
\hline Chl.a & 0.191 & 0.248 & 0.274 & 0.156 & 0.211 & 0.221 & 0.353 & 0.232 & 0.152 & 0.189 & 0.123 & 0.126 & 0.076 & 0.117 & $0.0 \vee 7$ & 0.113 & 0.170 \\
\hline Chl.b & 0.048 & 0.101 & 0.212 & 0.009 & 0.003 & 0.017 & 0.070 & 0.014 & 0.006 & 0.022 & 0.022 & 0.032 & 0.004 & 0.027 & 0.022 & 0.028 & 0.028 \\
\hline T. Chl. & 0.290 & 0.325 & 0.352 & 0.185 & 0.215 & 0.223 & 0.429 & 0.267 & 0.163 & 0.209 & 0.121 & 0.197 & 0.096 & 0.181 & 0.092 & 0.091 & 0.153 \\
\hline Carotenoides & 3.34 & 4.21 & 4.52 & 3.33 & 3.67 & 3.74 & 4.47 & 3.97 & 3.22 & 2.43 & 2.96 & 2.69 & 2.04 & 2.66 & 2.74 & 3.92 & 2.86 \\
\hline T. sugar & 0.247 & 0.243 & 0.241 & 0.255 & 0.238 & 0.245 & 0.230 & 0.239 & 0.234 & 0.236 & 0.222 & 0.229 & 0.263 & 0.228 & 0.227 & 0.231 & 0.274 \\
\hline
\end{tabular}

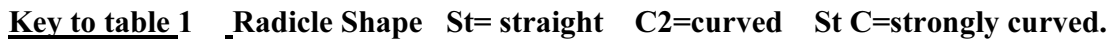

2ry. roots Sp= sparse $\quad M=$ moderate $\quad D=$ dense.

Leaf color $\mathrm{Ol}=$ olive green $\mathbf{G}=$ green.

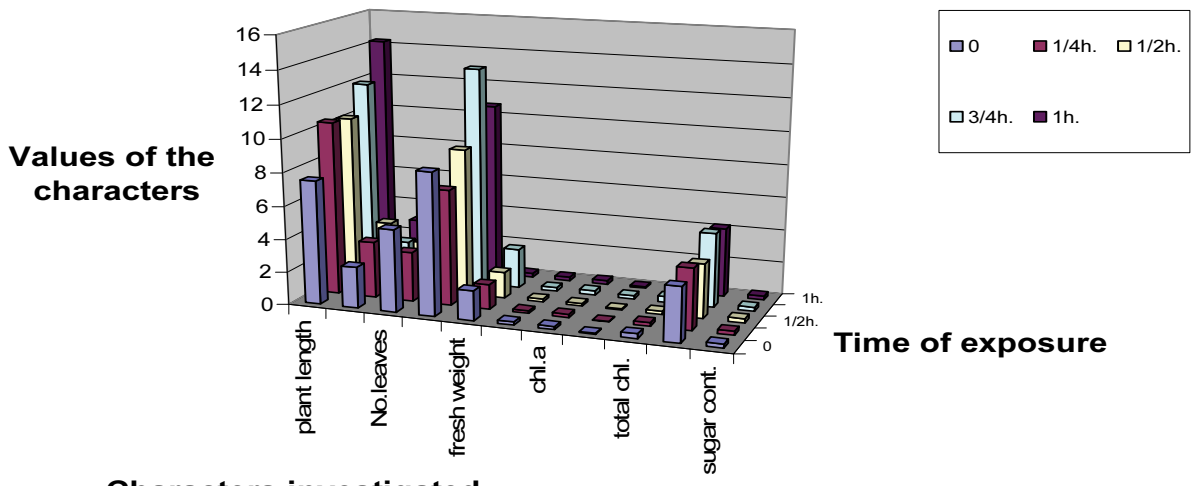

Characters investigated

Fig. 1. (1m). 


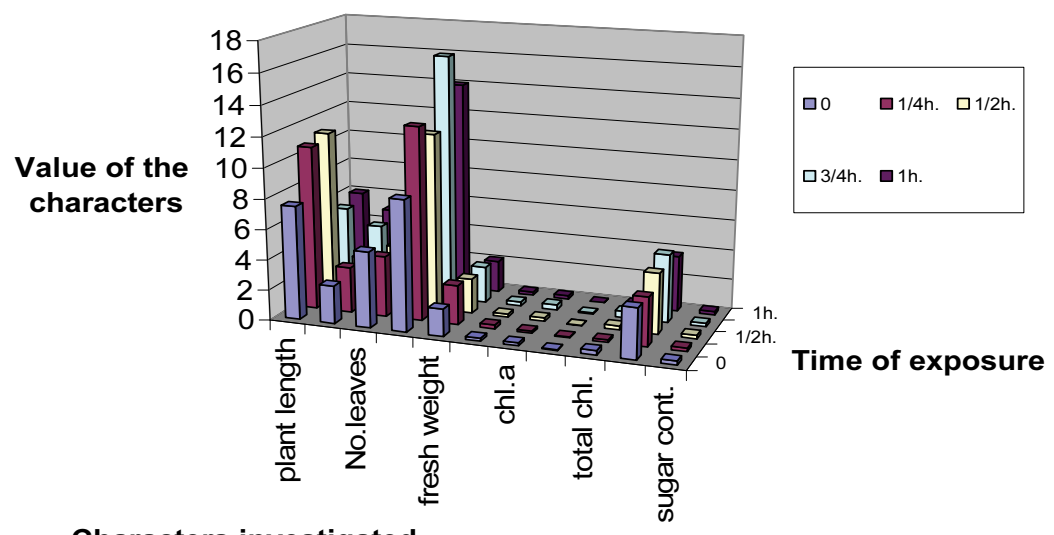

Characters investigated

Fig. 2. (2 ms).

Relations between distances and exposure times and characters of the tested plant after 45 days are drawn to illustrate how much the investigated character was affected by the time of exposure to the electric lamp. Figure 1 shows the values of the characters compared with the control under different exposure times at $1 \mathrm{~m}$ distance. From the Fig. 1- 4 it can be noticed that both plant length (char. 10), and leaf area (char. 12) are the most affected ones, as the maximum increase in plant length after $1 \mathrm{~h}$ exposure while that in leaf area after $3 / 4 \mathrm{~h}$ exposure at $1 \mathrm{~m}$ distance (Fig.1). While in 2 and $3 \mathrm{~m}$ distance the maximum increase in plant length was after $1 / 2 \mathrm{~h}$ exposure, and leaf area after $3 / 4 \mathrm{~h}$ exposure (Fig. 2)

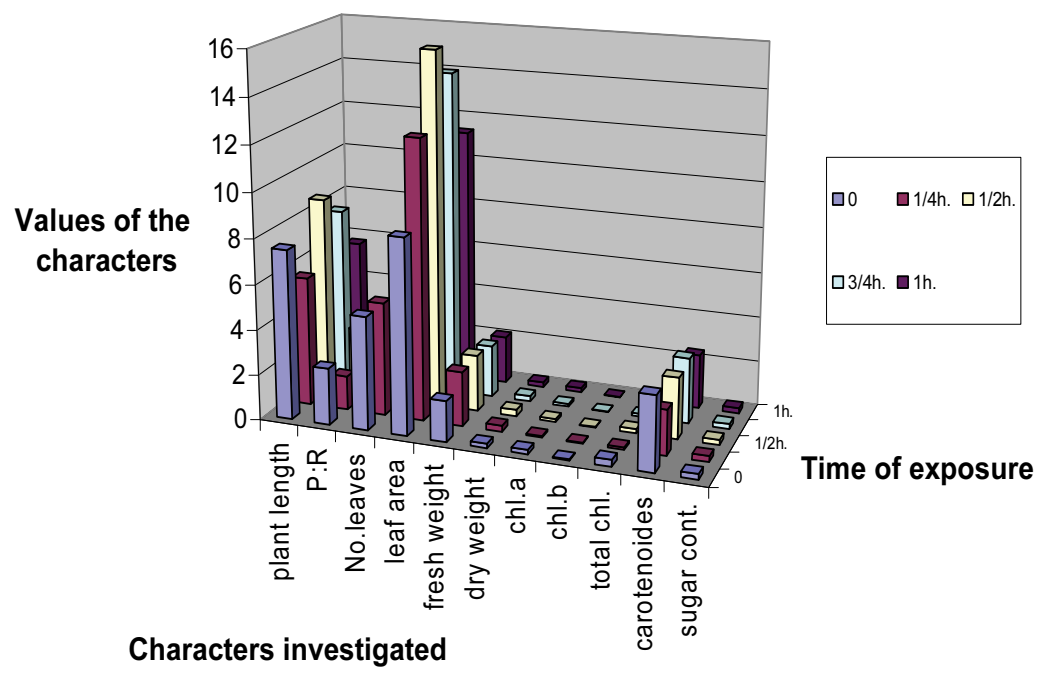

Fig. 3. (3 ms). 


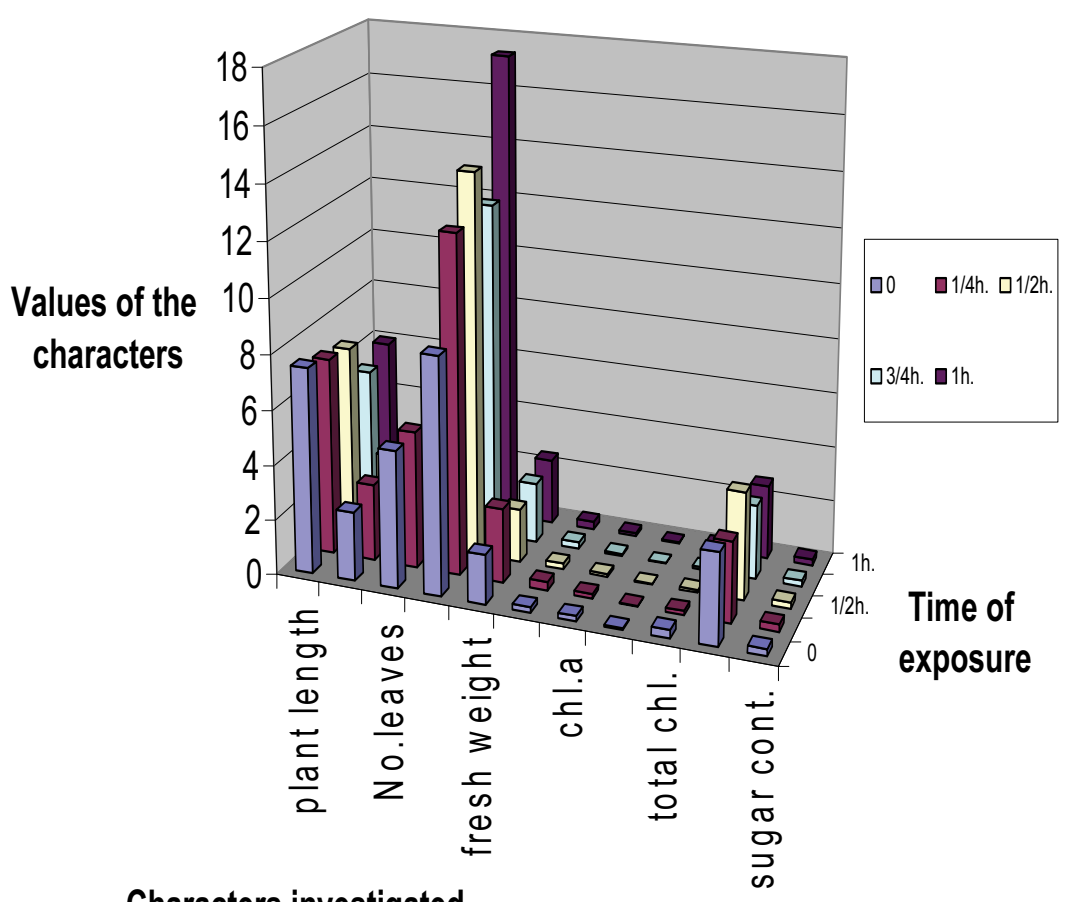

Characters investigated

Fig. 4. (4 ms).

and $1 / 2 \mathrm{~h}$ exposure (Fig. 3). At $4 \mathrm{~m}$ distance, there were no significant differences according to the time of exposure, except in leaf area only, where it increased significantly after $1 \mathrm{~h}$ exposure.

Analysis of the data using RSA and SF programs gave the illustrations of each character with the response to both time and distance. Meanwhile, the ideal length and exposure time for each character are calculated using ANN models and listed in Table 2. Table 2 shows that the best length of the plant can be given if the pots are put at 1 $\mathrm{m}$ distance from the electric lamp with an exposure time $0.25 \mathrm{~h}$, the same distance of the pot gave ideal carotenoides at $0.29 \mathrm{~h}$ exposure time, ideal chlorophyll $\mathrm{b}$ at $0.54 \mathrm{~h}$ exposure time, and ideal sugar contents at $0.62 \mathrm{~h}$ exposure time. Ideal values of total chlorophyll and chlorophyll a were at $2 \mathrm{~m}$ distance when exposed to the lamp for a period of 0.39 and $0.42 \mathrm{~h}$ respectively. $3 \mathrm{~m}$ distance of the pots gave ideal values for leaf numbers when exposed to the lamp for $0.4 \mathrm{~h}$, and fresh weight at $1 \mathrm{~h}$ exposure time. At $4 \mathrm{~m}$ distance only the dry weight gave ideal value when the plant was exposed for $0.25 \mathrm{~h}$. 
Analysis of the data using RSA and SF programs, gave the illustrations of each character with the response to both time and distance, as shown in Fig. 5-14. Meanwhile, the ideal length and exposure time for each character are calculated using ANN models, and listed in Table 2. Table 2 shows that the best plant length can be given when the pots are put $1 \mathrm{~m}$ distance from the electric lamp, with an exposure time of $25 \mathrm{~min}$. One meter distance pots can give ideal sugar contents when exposed for $62 \mathrm{~min}$, ideal carotene contents when exposed for $29 \mathrm{~min}$ and ideal chlorophyll $\mathrm{b}$ content when exposed for $54 \mathrm{~min}$. Two meters distance from the electric lamp can give us ideal contents of chlorophyll a when Cucumber plants were exposed to the lamp for 42 min and ideal total chlorophyll when exposed to the lamp for $39 \mathrm{~min}$. Three meters distance give ideal total numbers of leaves when exposed to the lamp for $4 \mathrm{~min}$ and ideal fresh weight when exposed to the lamp for one hour. Four meters distance from the lamp can give ideal leaf area and ideal dry weight are when exposed to the lamp for $25 \mathrm{~min}$ (Table 2).

Table 2. Calculated distance and time for the highest value for each param obtained from the ANN models (Germinated Seed experiment).

\begin{tabular}{|c|c|c|c|c|c|c|c|c|c|c|c|}
\hline Dist. & Time & chl-a & chl-b & T.chl & Carot. & Fr. Wt. & D.Wt. & sugar & PI.L. & $\begin{array}{c}\text { L. } \\
\text { No. }\end{array}$ & $\begin{array}{l}\text { L. } \\
\text { Ar. }\end{array}$ \\
\hline 1 & 0.25 & 0.243 & 0.123 & 0.265 & 4.221 & 2.390 & 0.230 & 0.249 & 14.23 & 3 & 12 \\
\hline 4 & 0.25 & 0.113 & 0.043 & 0.071 & 2.693 & 2.513 & 0.294 & 0.228 & 5.69 & 5 & $18^{*}$ \\
\hline 3 & 0.4 & 0.121 & 0.002 & 0.85 & 2.635 & 2.398 & 0.257 & 0.224 & 6.20 & $6^{*}$ & 14 \\
\hline 1 & 0.62 & 0.184 & 0.001 & 0.256 & 3.747 & 1.938 & 0.174 & $0.268^{*}$ & 8.81 & 4 & 10 \\
\hline 3 & 1 & 0.111 & 0.001 & 0.115 & 1.939 & 2.579* & 0.283 & \begin{tabular}{|l|l|}
0.267 \\
\end{tabular} & 5.89 & 5 & 13 \\
\hline 4 & 0.25 & 0.113 & 0.043 & \begin{tabular}{|l|}
0.071 \\
\end{tabular} & 2.693 & 2.513 & $0.294^{*}$ & \begin{tabular}{|l|l|}
0.228 \\
\end{tabular} & 5.69 & 5 & 18 \\
\hline 1 & 0.29 & 0.239 & 0.131 & 0.314 & 4.632* & 2.456 & 0.223 & 0.262 & 13.69 & 3 & 14 \\
\hline 1 & 0.54 & 0.260 & $0.368^{*}$ & \begin{tabular}{|l|l|}
0.309 \\
\end{tabular} & 4.632 & 2.250 & 0.204 & 0.238 & 11.65 & 3 & 15 \\
\hline 2 & 0.39 & 0.348 & 0.030 & $0.471 *$ & 4.243 & 2.509 & 0.277 & 0.233 & 5.95 & 5 & 16 \\
\hline 2 & 0.42 & $0.349 *$ & 0.032 & 0.470 & 4.282 & 2.507 & 0.778 & 0.278 & 5.96 & 5 & 16 \\
\hline
\end{tabular}

ANN models $=$ Analyses of Neural Net

Abbreviation used: chl-a = chlorophyll $\mathrm{a}, \mathrm{chl}-\mathrm{b}=$ chlorophyll $\mathrm{b}, \mathrm{T}$. chl. = total chlotophyll, Carot. = carotenoides, Fr. Wt. = fresh weight, D.Wt. = dry weight, Pl.L. = plant length, L.No. = numbers of leaves, L. Ar. $=$ Leaf area. 


\section{Discussion}

The continuous use of electric equipments and modern technology caused a lot of change in our biological processes and many questions arose in our minds about how much this technology will harm or benefit us. Many works such as Ref. [12- 18]. have been done to answer these questions on both plants and animals or even human beings, but all of them have used high voltage electric supplies or either high or extremely low frequencies electromagnetic fields. In this work we used an ordinary electric incandescent light bulb, which is normally placed in anywhere, to investigate how much the biological processes of germinating seeds of Cucumber will be affected by short and regular times of exposure at different distances from the lamp. The results obtained revealed that plant length, leaf area and photosynthetic pigments are the mostly affected characters by the exposure to the lamp at all the distance. Meanwhile both dry weight and sugar contents do not change, significantly, than the control plants. These mean that plant morphology can be altered by the exposure to the electric lamp as obtained by Bugbee ${ }^{[4]}$ where they found differences in radiation quality from the six most common electric lamps alter plant growth and internodes elongation. Fischer et al. ${ }^{[16]}$.Found that seedlings of sunflower and wheat plants when exposed to low frequency and force electric field found significant increases in total fresh weights, but dry weights and germination rates remained unaffected. These completely coordinate with our results and the changes happened in the increase in shoot length, leaf area and fresh weight by the exposure to the lamp, can be explained by the emission of heat energy from the incandescent light bulbs. This heat energy can ionize the molecules around the lamp and may cause a weak electric field around the lamp ${ }^{[3]}$. While the increase in the contents of chl.a in the 1 and $2 \mathrm{~m}$, chl.b and total chl. at $1 \mathrm{~m}(1 \& 3 / 4 \mathrm{~h}$. $)$ are due to the increase in photosynthetic rate by the direct exposure to the light as mentioned by Bugbee ${ }^{[4]}$.

The decrease in their amounts at 3 and $4 \mathrm{~m}$ may be due to the decrease in light intensity in long distance pots which cause biostimulation effects as mentioned by Kalinin ${ }^{[17]}$. The explanation of the insignificant effect of sugar contents in the treated plants can be due to the stress lie upon the plants which cause an increase in photosynthesis and in the same time increase in respiration in response to the stress happened. 
The ANN models and Table 2, in which the optimum distance and time of exposure to the $100 \mathrm{~W}$ electric lamp for each character show that the short time exposure in the four distance plants gave better values, except that in the fresh weight which give the best value at $3 \mathrm{~m}$ distance. These can be used to improve the status of the plants by using regular light supply with moderate exposure times as mentioned by Volk and Bugbee ${ }^{[19 \& 20]}$.

\section{References}

[1] International Programme on Chemical Safety. Environmental Health Criteria 160, Ultraviolet radiation (EHC $1602^{\text {nd }}$. Edition) (1994).

[2] Goldwasser, S.M., Fluorescent Lamps, Ballasts and Fixtures, Email:sam@stdavids.marconimed.com (1999).

[3] EMF Interface, Avoiding or eliminating some of the major electric and magnetic fields within your home and bedroom, Bioelectromanetics Health Effects Update (1998).

[4] Bugbee, B, Effect of Radiation Quality, Intensity, and Duration on Photosynthesis and Growth, pp: 39-50, In: T.W. Tibbitts (ed.), International Lighting in Controlled Environments Workshop, NASA-CP-95-3309 (1994).

[5] Berkeley, Energy a Sustainable Development, Email:Energy@ci.berkeley.ca.us (2002).

[6] Lorelei, I, Incandescent Light - The Healthier Alternative, Nexus Magazine 10(3 \& 4): 1-22 (2003).

[7] Smith, J.H. and Benitez, A., Chlorophylls analysis in plant materials. In: Peach, K. and Tracey, M.V. (eds.), Modern Methods in Plant Analysis, pp: 142-196, Sprunger-Verlag, Berlin (1955).

[8] Dubois, M., Gillies, K.A., Hamiltton, P.A., Rebers, R. and Smith, F., Colorimetric method for determination of sugars and related substances, Annal. Chem, 28:350. (1956).

[9] Dahlquist, G. and Bjorck, A. Numerical Methods, Englewood Cliffs, NJ: Prentice-Hall (1974).

[10] Johnson, L.W. and Ries, R. D., Numerical Analysis (2nd ed.), Reading, MA: Addison Wesley. (1982).

[11] Gerald, C.F. and Wheatley, P.O. Applied Numerical Analysis (4th ed.), Reading, MA: Addison Wesley (1989).

[12] Davies, A.M., Effects of $60 \mathrm{~Hz}$ electromagnetic fields on early, growth in three plant species and a replication of previous results, Bioelectromagnetics, 17(2): 154-161 (1996).

[13] Celestino, C., Picazo, M.L. and Toribio, M. Influence of Chronic Exposure to an Electromagnetic Field on Germination and Early Growth of Quercus suber Seeds: Preliminary Study, Electro- and Magnetobiology, 19(1): 115-120 (2000).

[14] Takimoto, K., Yaguchi, H. and Miyakoshi, J. Extremely low frequency magnetic fields suppress the reduction of germination rate of Arabidopsis thaliana seeds kept in saturated humidity. Bioscience Biotechnology and Biochemistry, 65(11): 2552-2554 (2001).

[15] Monselise, E.B-E., Parola, A.H. and Kost, D., Low-frequency electromagnetic fields induce a stress effect upon higher plants, as evident by the universal stress signal, alanine. Biochemical and Biophysical Research Communications, 302: 427-434 (2003).

[16] Fischer, G., Tausz, M., Kock, M, and Grill, D. Effects of weak $163 / 2 \mathrm{~Hz}$ magnetic fields on growth params of young sunflower and wheat seedlings, Bioelectromagnetics, 25(8): 638-641 (2004). 
[17] Kalinin, L.G., Boshkova, I.L., Panchento, G.I. and Kolomiichuk, S.G., The influence of a low- and high-frequency electromagnetic fields on seeds, Biofizika, 50(2): 361-366 (2005).

[18] Taia, W.K., Al-Zahrani, H.S. and Kotby, A.M. The Effect of Static Magnetic Forces on Water Contents and Photosynthetic Pigments in Sweet Basil Ocimum basillicum L. (Lamiaceae) J. Saud. Biol.Sci, 17 (1): public (2007).

[19] Volk, T. and Bugbee, B., Modeling light and temperature effects on leaf emergence rate in wheat and barley, Crop Science, 31: 1218-1224 (1991).

[20] Bugbee, B. and Monje, O., The optimization of crop productivity: Theory and validation Bioscience, 42: 494-502 (1992). 


\title{
تأثير الضوء المتوهج الناتج من المصباح الكهربائي على بعض الصفات الخضرية و الثكليـــة لنبــات الخيــار (الفصيلة القرعية)
}

\author{
وفاء كمال طايع، و صالحة محمد فادان \\ قسم النبات - كلبة العلوم - جامعة الإسكندرية- الإسكندرية- مصر

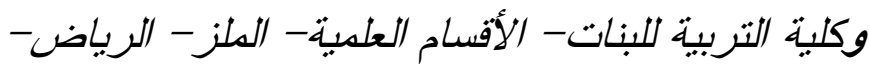 \\ المدلكة العربية السعودية
}

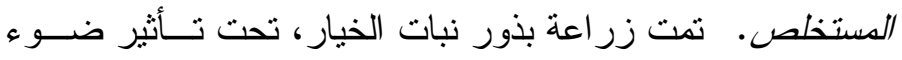

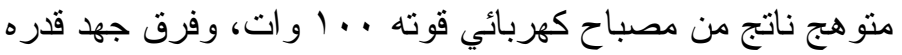

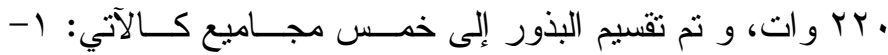

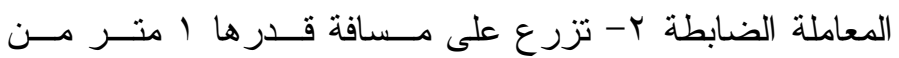

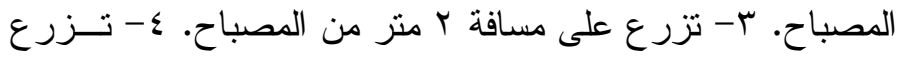

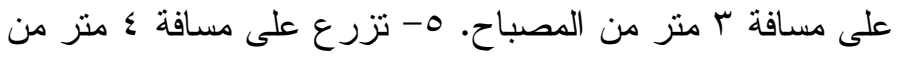

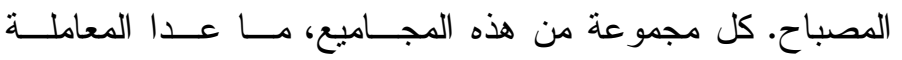

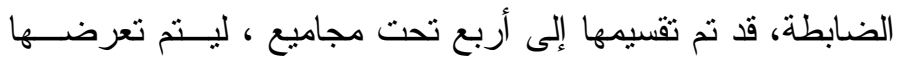

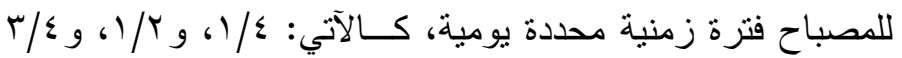

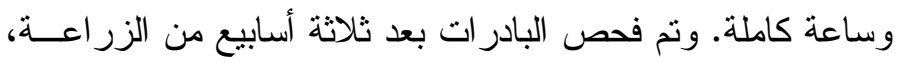

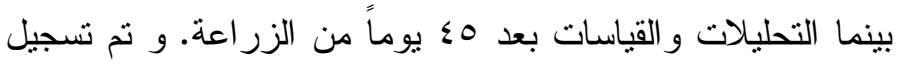

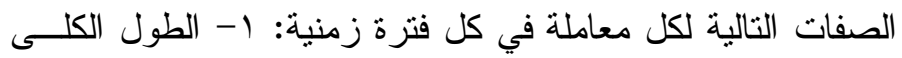

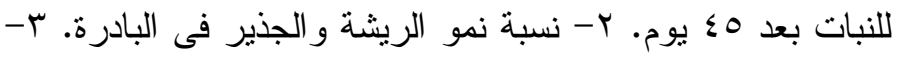

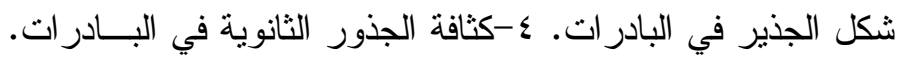

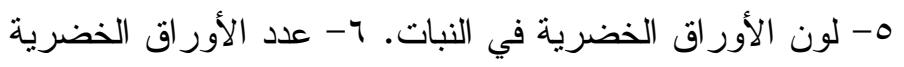


الكلية في النبات. V- مـسـاحة الأوراق الخـضرية. ـ ^- الــوزن

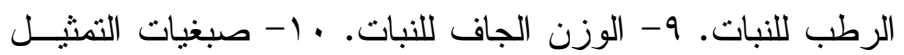

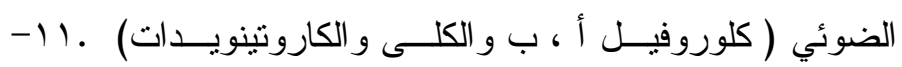
المحتوى الكلى للسكريات.

أوضحت النتائج المتحصل عليها أن تعـرض النبــات أثثـــاء الزر اعة لهذا الضوء المتوهج الناتج من المصباح الكهربائي، قد أثز

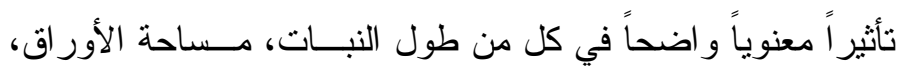

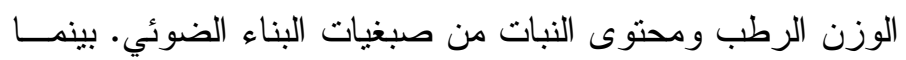

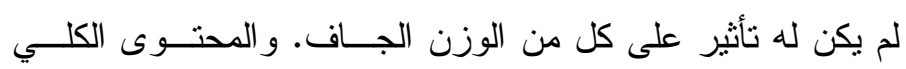

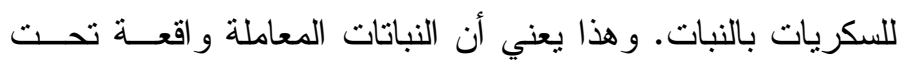

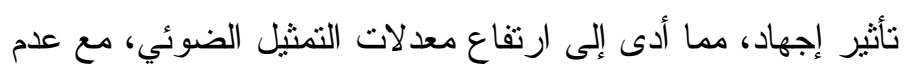

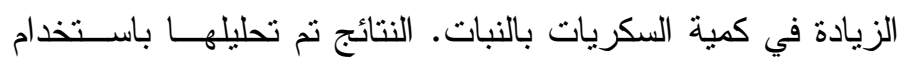

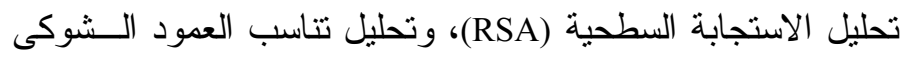

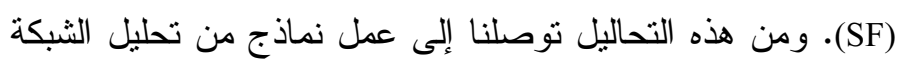

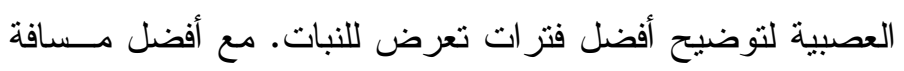

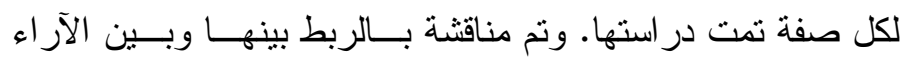
السابقة في هذا المجال. 